\title{
A INFLUÊNCIA DA GESTÃO DE PROJETOS DE P\&D EM UNIVERSIDADES PÚBLICAS NA DEFINIÇÃO DO MODELO DE UM ESCRITÓRIO DE GERENCIAMENTO DE PROJETOS
}

\author{
THE INFLUENCE OF R\&D MANAGEMENT PROJECTS IN PUBLIC UNIVERSITIES IN THE \\ DEFINITION OF THE MODEL OF A PROJECT MANAGEMENT OFFICE
}

José da Assunção Moutinho

Mestrando do Programa de Mestrado Profissional em Administração -

Gestão de Projetos da Universidade Nove de Julho (MPA-GP/UNINOVE).

\section{Claudia Terezinha Kniess}

Professora do Programa de Mestrado Profissional em Administração - Gestão de Projetos da Universidade Nove de Julho ( MPA-GP/ UNINOVE).

\section{Roque Rabechini Junior}

Professor do Programa de Mestrado Profissional em Administração - Gestão de Projetos da Universidade Nove de Julho (MPA-GP/ UNINOVE).

\section{RESUMO}

As universidades públicas brasileiras desempenham um papel cada vez mais expressivo no processo de inovação tecnológica do país. Esta responsabilidade implica a busca por recursos financeiros externos, com o objetivo de desenvolver projetos de Pesquisa e Desenvolvimento (P\&D). Contudo, essas instituições carecem de estrutura formal de gestão de projetos, visando garantir o sucesso desses empreendimentos. Neste contexto, o artigo discute como o ambiente público de P\&D pode influenciar a definição e classificação do modelo de um Escritório de Gerenciamento de Projeto. Utilizando a estratégia de estudo de caso, a investigação contou com entrevistas dos pesquisadores do laboratório e, como fonte documental, acesso a relatórios dos projetos concluídos. O estudo levou à conclusão de que o modelo de escritório adotado possui, simultaneamente, características de diversos níveis de classificação. Como resultado, ele é classificado como sendo do tipo híbrido, pois é diretamente influenciado pelas peculiaridades do ambiente, e que, além de gerenciar os projetos, o escritório também é responsável pelo cumprimento de aspectos legais, específicos para fomentos à pesquisa com recursos públicos.

Palavras-chave: escritório de gerenciamento de projetos;projetos de P\&D; universidade pública.

\section{ABSTRACT}

The Brazilian public universities play an increasingly significant role in the process of technological innovation in the country. This responsibility implies the search for external financial resources in order to develop projects of Research and Development (R\&D). However, these institutions lack the formal structure of project management in order to ensure the success of these ventures. In this context, the article discusses how the public environment of R\&D can influence the definition and classification of the model of a Project Management Office (PMO). Using the strategy of case study, the research included interviews of lab researchers and a documentary source, access to reports of completed projects. The study led to the conclusion that the model office adopted has both features of various levels of classification. As a result it is classified as being of hybrid type because it is directly influenced by the peculiarities of the environment and, in addition to managing the projects, the PMO is also responsible for the fulfillment of legal aspects, specific to stimulate research with public resources.

Keywords: project management office; R\&D projects; public university.

Endereços dos autores:

José da Assunção Moutinho

moutinho_pmp@yahoo.com.br

Claudia Terezinha Kniess

ctkniess@uninove.br

Roque Rabechini Junior

roquej@uninove.br 


\section{INTRODUÇÃO}

A estreita relação existente entre inovação e crescimento econômico se mostra evidente nos dias atuais. Em sua obra, Schumpeter (1934) demonstra a importância do papel desempenhado pela inovação, como agente criadora de ruptura do sistema econômico. O autor classifica a inovação em dois tipos: radical e incremental. A radical trata do desenvolvimento e introdução de um novo produto, processo ou forma de organização de produção completamente nova. A incremental é responsável pela introdução de um processo de melhoria em um produto, processo ou organização da produção, sem, no entanto, alterar a estrutura industrial.

Tanto a inovação radical quanto a incremental podem ter base na geração de conhecimento e esforços em Pesquisa e Desenvolvimento - P\&D (CAMPOS; CALLEFI; MARCON, 2009). Deste modo, sua importância é destacada como fonte geradora de conhecimento e tecnologia, sendo inegável para a competitividade das organizações e do desenvolvimento econômico das nações.

Assim como qualquer tipo projeto, os projetos de P\&D também são caracterizados pelos seus componentes de temporalidade e unicidade. Como peculiaridade e critério de distinção desta categoria de projeto, o Manual de Frascati (OCDE, 2002) indica a existência de um elemento de incerteza científica e/ ou tecnológica.

Considerando suas características específicas, Wheelwright e Clark (1992) propuseram uma distinção entre os projetos de P\&D e os demais, para evitar que se tenham as mesmas expectativas com os projetos de P\&D que há com os projetos de desenvolvimento comercial. Os autores destacam ainda que a metodologia de gerenciamento de projetos deve variar de acordo com o tipo de projeto a ser desenvolvido.

A criação de uma cultura de gerenciamento de projetos tem sido um tema bastante recorrente nas organizações contemporâneas, valendo-se do conceito de Escritório de Gerenciamento de Projetos (EGP) como instrumento primário na definição deste núcleo de competências. De acordo com sua definição funcional, o EGP auxilia os gerentes de projetos e os times da organização na implementação dos princípios, práticas, metodologias, ferramentas e técnicas do gerenciamento de projetos (KERZNER, 2009).

A realidade da cultura de projetos de P\&D também se faz presente nas universidades públicas brasileiras, as quais precisam constantemente buscar recursos financeiros junto a fontes externas de fomento, para garantir o desenvolvimento de seus projetos de pesquisa. Agências governamentais de fomento, como a Financiadora de Estudos e Projetos (Finep), o Conselho Nacional de Desenvolvimento Científico e Tecnológico (CNPq) e as Fundações Estaduais de Amparo à Pesquisa vêm demonstrando sua importância como instituições de apoio ao desenvolvimento tecnológico para as universidades.

Estudo realizado por Mowery e Sampat (2005) aponta que reduções dos recursos públicos por pesquisador, em face do aumento dos custos das pesquisas de ponta, têm feito as universidades adotarem uma postura mais agressiva e empreendedora na busca de novas fontes de recursos para os projetos de P\&D. No entanto, as instituições de ensino carecem de uma estrutura formal voltada a gestão desses projetos.

Com o objetivo de garantir o suporte necessário, inúmeras organizações implantam escritórios de projetos com distintas nomenclaturas. Suas distinções se fazem, de fato, pelos diferentes graus de autoridade e responsabilidade. Casey e Peck (2001) partem do pressuposto de que diferentes tipos resolvem diferentes problemas. Assim, apresentam três tipos de escritórios de projetos: "Estação Meteorológica", caracterizado pelo simples acompanhamento e informação, à alta administração, do andamento dos projetos, sem exercer nenhuma influência nos projetos analisados; o "Torre de Controle", responsável por estabelecer padrões, suporte e melhoria contínua à gerência de projetos; e o "Esquadrão de Comando", que tem como função assegurar a correta condução dos multiprojetos desenvolvidos nas organizações.

Entretanto, classificar um escritório de projetos de acordo com a terminologia proposta pela literatura nem sempre é tarefa simples, principalmente quando se encontra inserido em ambiente de P\&D. Surge então a questão principal desta pesquisa: como identificar o papel desempenhado pelo escritório de projeto em ambiente de projeto de P\&D e classificá-lo de acordo com os conceitos encontrados na literatura? 
É nesse contexto que o objetivo do presente artigo se insere: identificar como a gestão de projetos de P\&D em universidades públicas influencia a definição do modelo de escritório de gerenciamento de projetos. Como objetivos específicos, destacam-se: caracterizar e classificar o EGP, de acordo com os conceitos encontrados na literatura especializada no assunto.

Para alcançar os objetivos propostos, optou-se pela estratégia do estudo de caso. Serão levantados dados primários, por meio da realização de entrevistas com os pesquisadores do laboratório escolhido, e dados secundários, por meio da análise de evidências documentais. O quadro teórico constou com a revisão bibliográfica sobre dois principais conceitos: gestão de projeto de P\&D e escritórios de projetos.

\section{REVISÃO TEÓRICA}

Dois assuntos têm preocupado a comunidade interessada em entender a atividade de P\&D: sua constituição como atividade e as possibilidades de gerenciamento. Neste contexto, o quadro teórico abordando esses dois temas será apresentado.

\subsection{A Gestão de Projetos de P\&D}

A inovação tecnológica é um dos principais determinantes do desenvolvimento socioeconômico de qualquer país (JONES; WILLIAMS, 1999). De acordo com Schumpeter (1934), inovação tecnológica é definida como sendo a implementação de novos produtos ou processos, ou ainda mudanças significativas em produtos ou processos já existentes.

Para o Manual Frascati (OECD, 2002), a atividade de Pesquisa e Desenvolvimento compreende o trabaIho criativo, realizado em uma base sistemática, com o objetivo de incrementar o conhecimento existente, seja ele científico ou tecnológico, assim como o uso desse conhecimento para novas aplicações.

O Manual define que o termo P\&D envolve três tipos de atividade:

a) Pesquisa Básica: trabalho experimental ou teórico com a finalidade de compreender fenômenos e fatos observáveis, mas sem uma aplicação particular; b) Pesquisa Aplicada: investigação original com o intuito de adquirir novos conhecimentos direcionados a um objetivo prático; e,

c) Desenvolvimento Experimental: aplicação do conhecimento já adquirido com a finalidade de desenvolver novos materiais, produtos, processos, sistemas e serviços ou de melhorar os já existentes.

Valeriano (1998, p. 35) também conceitua o tema: "Consiste na busca sistematizada de novos conhecimentos, podendo situar-se no campo da ciência (projeto de pesquisa científica ou básica) ou no da tecnologia (projeto de pesquisa tecnológica ou aplicada)".

A gestão de atividades de P\&D se caracteriza como sendo uma das mais complexas nas organizações. Os pesquisadores e envolvidos em tais atividades são geralmente especialistas técnicos e, via de regra, demonstram pouca preocupação com questões referentes a prazo e custo dos projetos, pois colocam o avanço do estado-da-arte como prioridade, muitas vezes, até de maneira obsessiva.

Em estudo realizado por Sato e Dergint (2004), sobre a utilização do escritório de projetos para gestão de projetos tecnológicos em instituições de P\&D, destacam que o ambiente de pesquisa em P\&D está intimamente atrelado à criatividade de seus pesquisadores. Neste aspecto, coloca-se o fato de compartilhar os pesquisadores e gerentes de projeto em vários projetos, o que, segundo os autores, pode reduzir drasticamente a eficácia e a criatividade deles.

Isto não quer dizer que as pessoas deveriam ser alocadas a um único projeto por vez, pois muitas instituições perderiam a competitividade, principalmente com relação a custo, mas que esta situação de múltiplos projetos deve ser monitorada cuidadosamente, estabelecendo critérios formais para evitar conflitos e sobrecarga dos pesquisadores e gerentes. (IBID, p. 5)

Embora a competência de um pesquisador seja definida segundo critérios como a qualidade e continuidade de sua produção científica, experiência administrativa em instituições de ensino superior ou institutos de pesquisa, ou ainda na demonstrada competência em orientar estudantes e de ser capaz de conduzir a atuação de grupo de pesquisa, a falta de 
experiência em gestão de projetos é um fato marcante em inúmeros deles (RIBEIRO et al., 2010).

No campo de projetos de P\&D, existe uma particular dificuldade para se planejar exatamente as atividades que devem ser realizadas. Os cronogramas não contêm detalhes das atividades, mas somente marcos principais, que servem como balizadores para decisão de aportar mais recursos financeiros ou cancelá-los (SATO; DERGINT, 2004).

Outro aspecto que chama bastante atenção em projetos de P\&D são as características próprias de incertezas e inseguranças, significando que requerem elaboração e gerenciamento distintos. As formas tradicionalmente conhecidas de gestão de projetos não são suficientes para garantir o seu sucesso, dando lugar a uma abordagem adaptativa de gerenciamento de projetos com base em uma estrutura flexível (SHENHAR; DVIR, 2010). A natureza do risco e o grau de incertezas, associados aos projetos de P\&D, levam os pesquisadores a estudar e sistematizar métodos e processos, a fim de serem minimizadas as dificuldades intrínsecas à seleção de projetos (SOARES; QUADROS, 2007).

\subsection{Escritórios de Gerenciamento de Projetos}

A adoção de práticas em gestão de projetos vem se tornando cada vez mais difundida nas organizações e encontra no Escritório de Gerenciamento de Projetos (EGP) a possibilidade de sua materialização.

A definição de EGP é amplamente discutida na literatura, apontando para uma imprecisão no seu conceito. Tal indefinição deriva do fato de haver diversidade de significados e pontos de vista. Para Prado (2000), o escritório de projetos se caracteriza por ser um pequeno grupo de pessoas que têm relacionamento direto com todos os projetos da organização, seja prestando consultoria e treinamento, seja realizando auditoria e acompanhamento de desempenho dos projetos.

O EGP também pode ser definido como sendo uma entidade organizacional que provê foco institucional nos procedimentos de gerenciamento de projetos. Funciona como um mecanismo que permite a continuidade organizacional das experiências e lições aprendidas em gerenciamento de projetos, além de realizar atividades ligadas ao desenvolvimento de políticas, procedimentos, treinamentos, ferramentas e consultoria em gestão de projetos (RAD; RAGHAVAN, 2000).

No entanto, Verzuh (1999) consegue condensar as diversas definições sobre EGP. Em sua ótica, o EGP pode ser implementado de múltiplas maneiras, mas os dois fatores que regem as regras de um EGP são "responsabilidade" e "autoridade". Assim, torna-se possível criar uma grande variedade de combinações desse binômio, cada uma delas servindo para necessidades específicas da organização.

A identificação de padrões pode formar as bases para uma ou mais tipologias de EGP. Por meio de um estudo empírico, Hobbs e Aubry (2008) contribuíram para a compreensão do conceito de EGP, como aspecto importante para a prática do gerenciamento de projeto nas organizações. Sua concepção e gestão são complexos devido à grande variedade encontrada pelas diferentes organizações. Apesar da falta de consenso, tanto na sua estrutura, quanto nas funções, a tipologia de um EGP é definida levando-se em consideração suas diversas características e, essencialmente, sua realidade. Dentre as principais características a serem analisadas, cabe destacar: a estrutura da organização, o nível de maturidade em gestão de projetos, o apoio da cultura organizacional e a origem dos clientes - interna ou externa (CASEY; PECK, 2001).

O posicionamento adequado de um escritório de projetos na estrutura organizacional é fundamental. Neste sentido, Carvalho e Rabechini Jr. (2011, p.12) enfatizam que as "ações e processos em gerenciamento de projetos, com foco na eficácia, devem estar consolidados por meio de escritórios de projetos posicionados de forma estratégica, permitindo a integração dos vários esforços em gestão de projetos existentes numa organização". Investigações acerca da criação e utilização de EGPs, e de seus ambientes operacionais, apontam evidências de uma série de funções e serviços que influenciam no desempenho de projetos, por meio da demonstração de um grau de correlação (DAl; WELLS, 2004).

Dentre as principais funções e contribuições de um escritório de projetos, Kerzner (2009) destaca:

a) Padronização de planejamento e estimativas; 
b) Gerenciamento de recursos compartilhados entre todos os projetos administrados pelo EGP;

c) Padronização no controle e relatórios;

d) Elaboração de lições aprendidas;

e) Desenvolvimento de metodologia e padrões de gerenciamento de projetos;

f) Desenvolvimento de um plano de utilização dos recursos corporativos;

g) Realização de planejamento estratégico para o gerenciamento de projetos;

h) Coordenação e/ou condução de programas de treinamento em gerenciamento de projetos;

i) Realização ou participação no gerenciamento de portfólio de projetos.

Além das características descritas, é importante observar as particularidades da gestão de projetos de P\&D e o relacionamento existente entre os dois conceitos.

O quadro teórico apresentado, aponta para um ambiente favorável ao êxito do gerenciamento de projetos, disponibilizando, para isso, um conjunto de potenciais alternativas e ferramentas que necessitam ser adequadas a cada organização. Fundamentado nestes elementos conceituais, encontrados na literatura, foram definidos os objetivos deste artigo e tratados segundo os procedimentos metodológicos descritos a seguir, visando a responder a questão central.

\section{PROCEDIMENTO METODOLÓGICO}

A definição da estratégia de pesquisa é entendida como a designação das diferentes maneiras de abordar e analisar dados empíricos. Ela decorre de um minucioso processo de revisão da literatura e é acompanhado pela cuidadosa proposição das questões e objetivos da pesquisa (MARTINS; THEÓPHILO, 2009).

Após a definição do quadro teórico, a questão central a ser investigada foi definida: como identificar o papel desempenhado pelo escritório de projeto em ambiente de projeto de P\&D e classificá-lo de acordo com os conceitos encontrados na literatura?
Por se tratar de uma questão com enfoque em eventos contemporâneos, sem a possibilidade de manipulação dos comportamentos relevantes, Yin (2010) aponta para a utilização do estudo de caso como estratégia de pesquisa apropriada. Outro fato que corrobora a escolha dessa estratégia de investigação é que "os estudos de casos são comumente usados como método de pesquisa nas disciplinas de ciências sociais - psicologia, sociologia, ciência política, antropologia, assistência social, administração, administração pública, contabilidade e avaliação" (YIN, 2010, p.25, grifo nosso).

Como principais fontes de evidências, o estudo contou com entrevistas dos pesquisadores do laboratório e, como fonte documental, acesso a relatórios dos projetos concluídos. Vale ressaltar que o pontochave do estudo de caso é que a coleta de dados não seja realizada mecanicamente. É necessário que o pesquisador interprete as informações, à medida que forem sendo coletadas, e saber, imediatamente, se as diversas fontes de informação se contradizem e levam à necessidade de evidências adicionais. Deste modo, as entrevistas ocorreram intermeadas pela análise documental, ensejando na complementação de informações por parte dos entrevistados.

Quanto ao meio de investigação, foi utilizada a pesquisa de campo, pois foi realizada no local onde ocorre o fenômeno, ou seja, no laboratório de uma universidade pública. A abordagem utilizada na pesquisa foi essencialmente qualitativa, não havendo o tratamento estatístico dos dados. O instrumento de coleta utilizado contou com 34 questões, envolvendo funções típicas de gerenciamento de projetos, durante todo o ciclo de vida de projetos, com ênfase nas áreas do conhecimento, definida pelo PMI (2008). Foram ainda identificadas funções específicas desempenhadas pelo EGP, no contexto de uma organização pública com ênfase em gestão de projetos de P\&D. Ao todo, sete dos oito pesquisadores associados ao laboratório participaram da pesquisa, agregando informações importantes à realização do presente estudo.

Seguindo o procedimento, a confiabilidade dos resultados obtidos foi aumentada pela triangulação de múltiplas fontes de evidências, como ressaltado por Yin (2010, p. 142): “... um importante ponto forte da coleta de dados do estudo de caso é a oportunidade de usar diferentes fontes de evidências". Pos- 
teriormente, as informações levantadas foram submetidas a um processo de análise de conteúdo, sendo então confrontadas com a literatura, gerando, por conseguinte, os resultados descritos a seguir.

\section{RESULTADOS E DISCUSSÃO}

Inicialmente o objeto do estudo é caracterizado por meio de informações sobre o ambiente no qual se desenvolveu a investigação. Em seguida, procedese à descrição dos principais achados, seja por meio das entrevistas, seja pela pesquisa documental. A pesquisa culminou com a análise dos resultados à luz do referencial teórico previamente abordado.

\subsection{Caracterização do Objeto do Estudo}

Por meio de análise documental realizada, identificou-se que a Universidade, na qual está inserido o laboratório, objeto do presente estudo, iniciou suas atividades na década de 1950, no Distrito Federal. Criada a partir da fusão de quatro faculdades, a Instituição cresceu incorporando e criando novas unidades para atender não só às suas demandas, mas também as da comunidade.

Conforme o anuário estatístico 2011 da Universidade, no ano de 2010 havia 25.907 alunos, regularmente matriculados em cursos de graduação, 2.203, em cursos de especialização, e quase 2.862 alunos, nos cursos de mestrado e doutorado. Quanto ao quadro de funcionários, contam com 4.998, dentre os quais, mais de 1.821 são docentes.

Os dados estruturais encontram-se descritos na Tabela 1, divididos em três anos distintos: 2003, 2007 e 2010. Percebe-se claramente a ampliação significativa da infraestrutura de pesquisa, por meio do aumento da quantidade de laboratórios em funcionamento, assim como o substancial incremento de cursos de pós-graduação. Este fato traduz a consolidação de programas de capacitação e incentivo à dedicação à pesquisa implantada nos últimos anos na Universidade, firmando-se como uma das principais do país. Sua importância no espaço acadêmico brasileiro pode ser atestada pela qualidade da formação superior que oferece, pelo valor de sua produção científica, pelas centenas de projetos de extensão em desenvolvimento, pela promoção da cultura e pelos inúmeros serviços prestados à comunidade.

Quanto ao laboratório de pesquisa ora estudado, foi inaugurado em 1993, com a missão de ser referência no ensino, na pesquisa científica, na capacitação e atualização profissional na área de Física Médica. Atendendo às recomendações dos órgãos internacionais que regulamentam a utilização das radiações ionizantes na área de saúde, o laboratório de pesquisa delineou em seu objetivo, como eixo principal, centrarse na promoção e no desenvolvimento do conhecimento científico e tecnológico, visando a garantir o uso eficaz e seguro das radiações ionizantes pelos profissionais da área de radiologia, beneficiando, assim, toda a sociedade. Em decorrência, este laboratório se tornou referência na área, com forte sensibilidade às necessidades práticas da sociedade.

Tabela 1: Indicadores Estruturais da Universidade

\begin{tabular}{lrrr}
\hline Indicadores Estruturais & $\mathbf{2 0 0 3}$ & $\mathbf{2 0 0 7}$ & $\mathbf{2 0 1 0}$ \\
\hline Unidades acadêmicas & 29 & 29 & 30 \\
\hline Departamentos acadêmicos & 128 & 142 & 146 \\
\hline Laboratórios & 218 & 349 & 454 \\
\hline Cursos de graduação & 30 & 31 & 33 \\
\hline Cursos de especialização & 66 & 90 & 114 \\
\hline Cursos de mestrado & 33 & 41 & 44 \\
\hline Cursos de doutorado & 15 & 23 & 27 \\
\hline
\end{tabular}

Na sua vertente acadêmica, participa do Programa de Pós-Graduação em Biologia, atuando, desde sua criação, na formação de pesquisadores nas áreas das Ciências Biofísicas e da Saúde. O laboratório já propiciou o desenvolvimento de aproximadamente 30 dissertações de mestrado e 20 teses de doutorado, contando ainda com a publicação de mais de 120 artigos científicos nacionais e internacionais, por meio de significativa contribuição de seus colaboradores. Conta atualmente com uma equipe composta por oito pesquisadores, três alunos de doutorado, quatro alunos de mestrado, quatro de pré-mestrado e três alunos de iniciação científica.

Criado em 2005, o Escritório de Projetos tem por objetivo gerenciar os projetos de P\&D desenvolvidos no âmbito do laboratório, servindo como elo integra- 
dor entre a direção, pesquisadores e alunos envolvidos. Diretamente ligado à direção, tem como função, materializar a captação dos recursos financeiros necessários, seja por meio de editais específicos, lançados por agências de fomento, seja de modo proativo, por meio da apresentação de projetos.

Elabora, em conjunto com os pesquisadores, os projetos a serem submetidos, disponibilizando assim, um conjunto de conhecimento inerente à gestão de projetos. O escritório ainda é responsável pelo monitoramento dos projetos, cumprimento dos prazos legais, elaboração da prestação de contas dos recursos aportados e por todo o processo de aquisição de equipamentos importados, junto à universidade.

\subsection{Resultados Obtidos}

Uma vez apresentados o problema, a metodologia de pesquisa e a contextualização do objeto de estudo, faz-se necessário apresentar as evidências levantadas e proceder à sua análise. Para isso são considerados, inicialmente, os aspectos gerais do ambiente estudado, seguidos da apresentação de dados sobre o entendimento do papel do EGP no laboratório.

O baixo nível de integração e fraco entendimento dos processos foi, por muito tempo, fator restritivo para o incremento de projetos de P\&D, no laboratório de pesquisa objeto de estudo. A falta de um setor específico de gestão dos projetos resultava em planejamento e controle físico-financeiros insipientes, dos recursos oriundos das agências de fomento. As informações acerca dos empreendimentos desenvolvidos eram fragmentadas, e não havia registro das lições aprendidas, após serem concluídos. A prestação de contas dos convênios junto aos órgãos de fomento também era prejudicada pela falta de mecanismos efetivos de monitoramento dos projetos.

No entanto, com a perspectiva de desenvolvimento de novos projetos de pesquisa no laboratório, a necessidade da aplicação de práticas de gestão de projetos se tornou cada vez mais evidente. As demandas detectadas pelos pesquisadores careciam de uma abordagem técnica em gerenciamento dos projetos. Inúmeros editais lançados pelas agências de fomento necessitavam da apresentação de projetos adequadamente elaborados, os quais envolviam definição de objetivos precisos, recursos técnicos, financeiros e dimensionamento de prazos, à luz de critérios previamente estabelecidos.

Por meio do levantamento de registros em arquivos, junto ao setor de projetos, verificou-se que a quantidade de projetos de pesquisa iniciados por ano também aumentou significativamente, quando levado em consideração o período compreendido entre 2004 e 2011 (Gráfico1).

Gráfico 1 : Quantidade de projetos de pesquisa iniciados por ano.

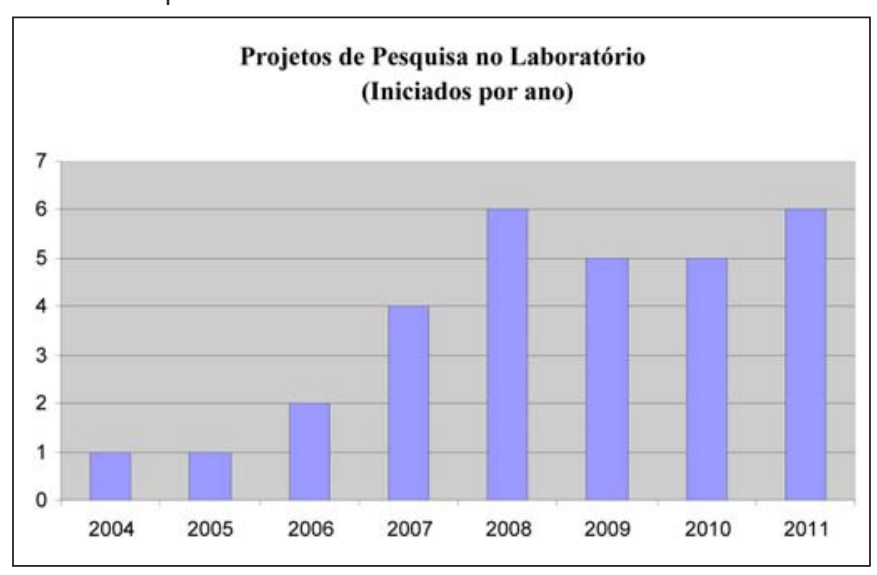

Esse fato é resultado, principalmente, do incremento de novas plataformas tecnológicas, possibilitando novas pesquisas, da retenção de talentos profissionais oriundos dos cursos de mestrado e doutorado, oferecidos em parceria com o programa de pósgraduação Stricto Sensu, e do elevado grau de notoriedade do principal pesquisador e coordenador do laboratório. Em decorrência, a quantidade de projetos simultaneamente executados cresceu, justificando plenamente a implantação de um órgão específico para suportar esses projetos. O Gráfico 2 demonstra o crescimento ao longo dos anos, no período caracterizado entre 2004 e 2011.

Algumas outras variáveis devem ser consideradas. De acordo com o levantamento de informações realizadas no escritório de projetos, o tempo médio de execução dos projetos é de 21 meses. No entanto, quando considerado o momento de sua elaboração, até a conclusão da prestação de contas junto ao órgão de fomento, o prazo médio de um projeto passa a ser de 29 meses. É justamente nos períodos anterior 
e posterior ao desenvolvimento do projeto que o escritório desempenha um papel fundamental, pois garante aos projetos o cumprimento dos requisitos legais, inerentes ao ambiente público.

Gráfico 2: Quantidade de projetos de pesquisa em execução por ano.

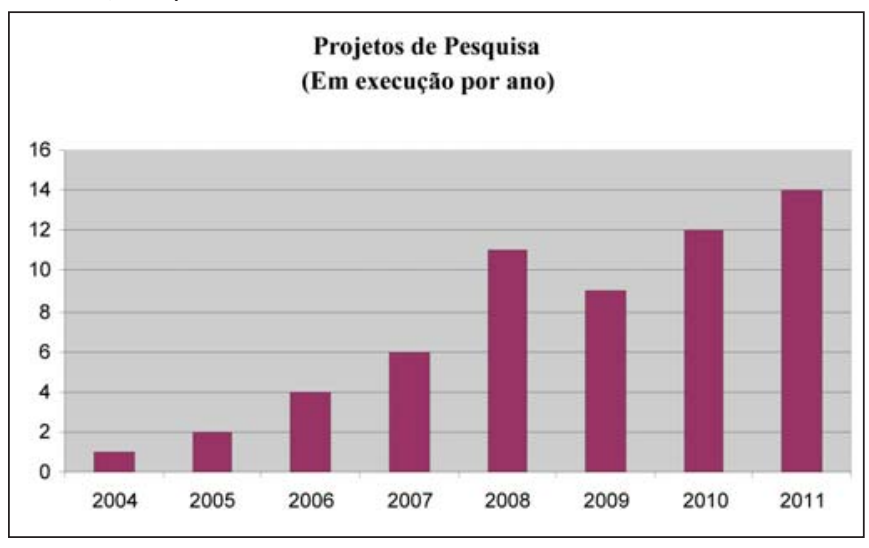

O fato de o laboratório ter um setor específico, na sua estrutura, responsável pela integração e gestão dos projetos, propicia um ambiente favorável à qualidade, pois disponibiliza uma infraestrutura e um suporte organizacional sistemático adequado ao alcance dos objetivos previamente estabelecidos.

\subsubsection{Funções Gerenciais}

Os resultados da pesquisa indicam que, dependendo do estágio no qual o projeto se encontra, o escritório de projetos desempenha papéis com distintas intensidades. Durante o planejamento, o EGP presta a ele uma considerável contribuição, pois, em conjunto com os pesquisadores, elabora e submete os projetos de P\&D aos órgãos de fomento. A pesquisa revela que as áreas de conhecimento mais enfatizadas são escopo, prazo e custo, visto que representam geralmente a tríade restritiva dos editais. Em oposição, as áreas de conhecimento, qualidade e riscos não são tratadas pelo escritório, por serem tecnicamente abordadas, ficando, então, a cargo dos coordenadores dos projetos. Os resultados também indicam que, quando se abordam os aspectos formais de gerenciamento de projeto, como a utilização de ferramentas, técnicas, desenvolvimento de metodologia e padrões para gerenciamento de projetos, estes não são claramente percebidos.
Durante a execução dos projetos de P\&D pelo laboratório, verifica-se que há uma discreta participação do EGP nas atividades de gestão, residindo apenas no aspecto de orientação da sua execução, sem entrar em qualquer tipo de detalhamento. Dimande e Andrade (2006, p. 4) apontam para o mesmo fato:

\section{Originalmente, não cabe ao EGP gerenciar a execução dos projetos (Bernstein, 2000, Robertson, 2004), uma vez que o EGP não é uma unidade que se propõe a substituir tanto dirigentes como gerentes de projeto, no entanto, ele auxilia os gerentes de projetos na tomada de decisão (CLELAND; IRELAND, 2002).}

Neste estágio, as funções específicas de: garantia da qualidade, mobilização de equipes ou ainda gerenciamento das expectativas das partes interessadas, são apontadas como não desempenhadas pelo escritório de projetos. Essas observações se justificam pelo fato de os padrões de qualidade serem implementados diretamente pela coordenação de projetos, e ainda não ser uma prática explícita o gerenciamento das expectativas das partes interessadas. No entanto, ainda neste grupo de processos, o papel do EGP ganha um destaque fundamental, durante a realização das aquisições. Todo o trâmite referente à compra de equipamentos importados é realizado pelo escritório de projetos, não só devido à suas particularidades, mas também pela necessária interação com diversos setores da Universidade.

No estágio seguinte, denominado monitoramento e controle, verifica-se maior grau de envolvimento do escritório de projetos na verificação do escopo, do prazo e dos custos. Esse fato está diretamente relacionado a outro quesito altamente percebido: formalizar e monitorar as mudanças necessárias junto aos órgãos de fomento. Ainda como função neste grupo de processos, destaca-se o papel de manter a direção do laboratório informada acerca do andamento de cada um dos projetos de P\&D em execução. Por outro lado, as funções de controle da qualidade e monitoramento dos riscos não são claramente percebidas como sendo desempenhadas pelo escritório de projetos.

Durante o estágio de encerramento do projeto, duas funções merecem ser destacadas. A primeira delas é caracterizada pelo registro e armazenamento das lições aprendidas. Todas as informações referentes aos projetos, sejam de linhas de base de estimativas, alterações, resultados alcançados, relatórios 
científicos e financeiros, são organizadas e armazenadas no EGP do laboratório, para ser consultadas como informações históricas sobre os projetos desenvolvidos. Em sua pesquisa, Dimande e Andrade (2006) destacam essa prática como fundamental, pois, via de regra, privilegia-se consideravelmente a documentação financeira, com quase total detrimento da documentação técnica, fazendo com que a organização perca seu maior ativo - tratando-se de uma instituição de P\&D -, que é a memória dos projetos: como foram desenvolvidos, etapas pelas quais passaram, dificuldades enfrentadas, etc. Portanto, implicam uma considerável perda de conhecimento adquirido.

Já a segunda função diz respeito à realização tempestiva da prestação de contas junto às agências de fomento. Qualquer despesa realizada durante a vigência do projeto, necessariamente, precisa estar de acordo com os valores orçados, devendo ainda ser previamente autorizada para cada grupo de elemento de despesa, à luz dos aspectos formais da contabilidade pública. O desrespeito a essa regra básica coloca o pesquisador em uma delicada situação, com sérias implicações, inclusive de ressarcimento ao erário público dos recursos malversados. Cabe ainda ressaltar que a inadimplência na prestação de contas também inabilita o pesquisador-coordenador a concorrer a recursos para o desenvolvimento de novos projetos. Dependendo do tipo de pesquisa, a descontinuidade de aporte de recursos financeiros pode significar um enorme prejuízo ao avanço da ciência e da tecnologia.

\subsubsection{Aspectos Gerais}

Os resultados obtidos apontaram que houve consenso no que diz respeito ao escritório de projetos também implementar e operar um sistema de informações dos projetos. Um sistema gerencial proprietário, desenvolvido no próprio laboratório, considerou as características peculiares do ambiente: um laboratório de pesquisa em uma universidade pública. Esse sistema permite gerenciar os projetos em suas diversas fases, durante o ciclo de vida, indo desde sua elaboração à efetiva prestação de contas.

A gestão de um plano de utilização dos recursos corporativos também fica a cargo do escritório de projetos, pois como lida com todos os projetos do laboratório, tem a visão necessária para alocar os recursos compartilhados.

De acordo com os entrevistados, o quesito relativo a treinamento em gestão de projetos foi identificado como não contemplado pelo setor de projetos. De fato, é um dos aspectos ainda pouco explorados no laboratório, e que parece merecer mais atenção. Esta questão já havia sido abordada no estudo realizado por Dimande e Andrade (2006), indicando forte necessidade de se capacitar pesquisadores em técnicas de gestão.

\subsection{Discussão dos Resultados}

Após a coleta de evidências e descrição dos principais achados, torna-se necessário realizar uma análise dos resultados à luz do referencial teórico, previamente abordado, com o intuito de atender ao objetivo do presente artigo, que é compreender o papel desempenhado pelo escritório de projetos no gerenciamento de projeto de P\&D.

A seguir, apresenta-se uma análise, por meio do Quadro 1, confrontando resultados alcançados com a coleta de informações junto aos pesquisadores do laboratório, com o referencial teórico de classificação dos tipos de EGP, de acordo com Casey e Peck (2001), e Crawford (2002).

É pertinente ressaltar que a terceira coluna do Quadro 1, intitulada "Observado no EGP do laboratório pelos seus pesquisadores", é resultante da maioria das respostas dos entrevistados sobre as características específicas identificadas.

Deste modo, conclui-se que, à luz dos autores, o escritório de projetos do laboratório não pode ser classificado em um único nível, pois apresenta tanto características de escritórios de controle, como de suporte e estratégico de projetos. Por meio de estudo realizado, Dinsmore (1999) já identificava essa possibilidade, afirmando que, de fato, as implementações de escritórios de projetos se direcionam para soluções alternativas e híbridas. Ainda de acordo com esse autor, cada organização busca implementar a solução que garanta um melhor desempenho, adaptando as funções, responsabilidades e atividades da abordagem padrão. Por este motivo, a forma de materialização de EGP está diretamente relacionada às necessidades específicas do ambiente. 
Em pesquisa realizada por Hobbs e Aubry (2007), pioneira em analisar 500 escritórios de gerenciamento de projetos em profundidade, constatou-se uma significativa variação na estrutura, papéis assumidos e no valor percebido dos EGPs, corroborando os fatos identificados no presente artigo. Anteriormente a este estudo, as funções dos EGPs eram agrupadas e classificadas sem, no entanto, a realização de nenhuma pesquisa para esgotar o mapeamento de funções e criar uma taxonomia.

Além das funções e características descritas no Quadro 1, identifica-se, pela análise dos dados coletados, que o EGP do laboratório também é responsável por outras funções gerenciais específicas: a) Elaborar, em conjunto com os pesquisadores, os projetos a serem submetidos às agências de fomento;

b) Definir os custos e cronogramas dos projetos;

c) Orientar e gerenciar, com os pesquisadores, a execução dos projetos;

d) Formalizar junto às agências de fomento as mudanças necessárias;

e) Manter a direção informada quanto ao status do projeto;

f) Encerrar o projeto, realizando prestação de contas junto às agências de fomento.

Quadro 1: Comparativo referencial teórico versus laboratório

\begin{tabular}{|c|c|c|}
\hline Nível & Característica & $\begin{array}{l}\text { Observado no EGP } \\
\text { do Laboratório pelos } \\
\text { seus pesquisadores }\end{array}$ \\
\hline \multirow{6}{*}{$\begin{array}{l}\text { Escritório de Controle } \\
\text { de Projetos }\end{array}$} & Confecção de relatórios de progresso & NP \\
\hline & Confecção de relatórios de custos e prazo & MP \\
\hline & Confecção de relatórios de riscos & NP \\
\hline & Manutenção de base de dados histórica e lições aprendidas & FP \\
\hline & $\begin{array}{l}\text { Confecção de relatórios de desempenho segundo indicadores } \\
\text { previamente definidos }\end{array}$ & NP \\
\hline & Monitoramento dos resultados do projeto & MP \\
\hline \multirow{6}{*}{$\begin{array}{l}\text { Escritório de Suporte } \\
\text { de Projetos }\end{array}$} & Treinamento em gerenciamento de projetos & NP \\
\hline & $\begin{array}{l}\text { Estabelecimento e verificação do cumprimento de padrões e métricas } \\
\text { de gerenciamento de projetos }\end{array}$ & NP \\
\hline & $\begin{array}{l}\text { Possibilidade do alinhamento dos projetos às estratégias do } \\
\text { departamento ou divisão }\end{array}$ & FP \\
\hline & Controle e armazenamento das lições aprendidas e dos relatórios & FP \\
\hline & Definição, implementação e controle de mecanismos de mudanças & LP \\
\hline & Papel de mentor para projetos com problemas & NP \\
\hline \multirow{5}{*}{$\begin{array}{l}\text { Escritório Estratégico } \\
\text { de Projetos }\end{array}$} & Padronização do gerenciamento de projetos & NP \\
\hline & Identificação, priorização e seleção de projetos & NP \\
\hline & Gerenciamento corporativo de recursos & MP \\
\hline & Implantação e manutenção de um sistema de informações & MP \\
\hline & Alinhamento dos projetos à estratégia corporativa & NP \\
\hline
\end{tabular}

Legenda: NP - (Não percebido); LP - (Ligeiramente percebido); MP - (Medianamente percebido);

FP - (Fortemente percebido) 
Essas atribuições ficam a cargo do EGP, visto que os coordenadores dos projetos de pesquisa não possuem essas habilidades específicas. Tal fato corrobora o estudo realizado por Ribeiro et al. (2010), que aponta a falta de experiência do coordenador em práticas de gerenciamento de projetos.

\section{CONCLUSÕES}

O objetivo do artigo foi caracterizar como o ambiente de projeto de P\&D influencia na definição de um escritório de projetos. Devido a diversas características peculiares, o estudo levou à conclusão de que se trata de um tipo híbrido de escritório de projeto, por apresentar atributos dos vários tipos descritos na literatura.

O estudo evidencia que as instituições públicas de pesquisa também devem adequar os seus ambientes, com a implantação de escritórios de projetos, com vistas a aumentar a probabilidade de ter um fluxo contínuo de projetos gerenciados com sucesso, in- crementando assim, sua qualidade percebida, já que é entendida como um diferencial estratégico.

Como contribuição, o artigo discutiu o gerenciamento de projetos em um ambiente público, acadêmico e de pesquisa. No país, esse tipo de ambiente carece de estudos, pois possui um conjunto de características bem peculiares, com a ampla participação de pesquisadores e alunos de pós-graduação, fato que se reflete diretamente no modo como a gestão de projetos é abordada. A falta de um corpo técnico especializado em gestão de projetos também é um fator limitante para a disseminação dessa cultura.

O presente artigo se limitou a analisar o entendimento dos principais pesquisadores em relação às atividades do escritório de projetos. De toda sorte, a existência de técnicas e ferramentas de gerenciamento de projetos eleva continuamente a maturidade em direção a patamares mais elevados. Uma análise mais detalhada da maturidade do escritório de gerenciamento de projetos, poderia ser apropriada para descrever o mapa lógico de caminho para o incremento da qualidade dos serviços prestados pelo setor.

\section{REFERÊNCIAS}

CAMPOS, A.; CALLEFI, P.; MARCON, A. O Brasil no contexto mundial da inovação tecnológica. Pesquisa e Debate. São Paulo, v. 20, nº 1 (35), p. 73-96, 2009.

CARVALHO, M.; RABECHINI Jr., R. Fundamentos em gestão de projetos: construindo competências para gerenciar projetos. 3 ed. São Paulo: Atlas, 2011.

CASEY, W.; PECK, W. Choosing the right PMO setup. PM Network. Illions, p.40-47, Feb. 2001.

CRAWFORD, J. The Strategic Project Office: A guide to improving organizational performance. New York: Marcel Dekker Inc, 2002.

DAI, C.; WELLS, W. An exploration of project management office features and their relationship to project performance. International Journal of Project Management. v. 22, Issue7, p. 523-532, 2004.

DIMANDE, C.; ANDRADE, R. Proposição de uma alternativa de gestão de projetos para uma organização de pesquisa agroindustrial. In: XIII SIMPEP.
Bauru, SP, 6 a 8 de nov. 2006 Anais... São Paulo, 2006.

DINSMORE, P. Winning business with enterprise Project Management. New York. Amacon, 1999. Disponível em <http://books.google.com.br/books? $\mathrm{id}=\mathrm{BqN0P7y}$ Q6ukC $\&$ printsec $=$ frontcover $\& \mathrm{dq}=$ Winning+business+with+enterprise+Project+ Management\&hl=en\&sa=X\&ei=MqtxUZT4F6TbOwGw 6oCIDA\&ved=0CDAQ6AEwAA >. Acesso em: 02/ $10 / 2011$.

HOBBS, B.; AUBRY, M. A Multi-phase research program investigating Project Management Offices (PMOs): The results of phase 1. Project Management Journal, v. 38, p. 74-86, 2007.

HOBBS, B.; AUBRY, M. An Empirically Grouded Search for a Typology of Project Management Offices. Project Management Journal. v. 39. Supplement S69S82, 2008. 


\section{REFERÊNCIAS}

JONES, C.; WILLIAMS, J. Too much of a good thing? The economics of investment in R\&D. NBER Working Paper Series, n. 7283, 1999.

KERZNER, H. Project Management: A systems approach to planning, scheduling and controlling. 10th ed. New York: JohnWiley \& Sons, Inc. Hoboken, 2009.

MARTINS, G.; THEÓPHILO, C. Metodologia da investigação científica para ciências sociais aplicadas.

2. ed. São Paulo: Atlas, 2009.

MOREWY, D.; SAMPAT, B. Universities in national innovation systems. In: FAGERBERG, J.;MOWERY, D.; NELSON, R. (Eds.). The Oxford handbook of innovation. Oxford: Oxford University, p. 209-239, 2005.

ORGANIZAÇÃO PARA A COOPERAÇÃO E DESENVOLVIMENTO ECONÔMICO - OECD. Manual de Frascati: Metodologia proposta para a definição da investigação e desenvolvimento experimental. 2002. Disponível em <www.mct.gov.br>. Acesso em: 8/12/2011.

PRADO, D. Gerenciamento de projetos nas organizações. Belo Horizonte: Desenvolvimento Comercial, 2000.

RAD, P.; RAGHAVAN, A. Establishing an Organizational Project Office. AACE International Transactions, 2000.

RIBEIRO, E; MORAES, J. RUIZ, A. Identificação e caracterização de dificuldades na execução de projetos de P\&D financiados pela FINEP. In: VI Congresso Nacional de Excelência em Gestão, 5, 6 e 7 de ag. 2010, Niterói. Anais eletrônicos... Niterói, 2010. Disponível em <http://www.excelencia emgestao.org/pt/edicoes-anteriores/vi-cneg/ anais.aspx>. Acesso em: 20/12/2011.

SATO, C.; DERGINT, D. A utilização do escritório de projetos para a gestão de projetos tecnológicos em instituições de pesquisa e desenvolvimento (P\&D). In: $4^{\circ}$ Congresso ABIPTI 2004, 2004, Belo Horizonte, MG. Tecnologias para inclusão social: o papel dos sistemas de Ciência, Tecnologia e Inovação. Brasília: ABIPTI, 2004. v. 1. p. 1-12, 2004.

SHENHAR, A.; DVIR, D. Reinventando gerenciamento de projetos: A abordagem diamante ao crescimento e inovação bem-sucedidos. São Paulo: M. Books, 2010.

SOARES, F; QUADROS, R. Avaliação do processo de gerenciamento de portfólio de projetos de P\&D: Caso CEMIG. In: XII Seminario Latino-lberoamericano de Gestión Tecnológica - ALTEC 2007. 26 a 28 de set. 2007, Buenos Aires. Anais... Buenos Aires: ALTEC, 2007.

VALERIANO, D. Gerência em projetos: pesquisa, desenvolvimento e engenharia. São Paulo: Makron Books, 1998.

SCHUMPETER, J. The theory of economic development. Cambridge MA: Harvard University Press, 1934.

VERZUH, E. The fast forward MBA in a Project Management. New York: John Wiley \& Sons, 1999.

WHEELWRIGHT, S; CLARK, K. Creating project plans to focus product development. Harvard Business Review, mar/apr 1992.

YIN, R. Estudo de caso: planejamento e métodos. 4 ed. Porto Alegre: Bookman, 2010. 